\title{
The use of hormonal therapy in "andropause": the pro side
}

\section{Alvaro Morales, MD}

See related article on page 52

"An error is the more dangerous the more truth it contains."

- Henri-Frédéric Amiel

The purpose of the section is to encourage vigorous and informed discussion on controversial issues in urology through the presentation of diverse opinions. We aim for a dispassionate discussion of controversies, recognizing that strong passions may exist in support of some positions.
A Ithough the discovery and synthesis of testosterone and other androgens took place more than 80 years ago, the controversy over their significance, applications and use is no less intense today than it was then. The introduction of injectable forms of testosterone in the first half of the 20th century created great expectations and a rush to treat all sorts of disparate conditions unrelated to a deficiency in testosterone production. The false hopes and misunderstandings due to androgen use and abuse in the absence of hypogonadism resulted in frustration and disappointment for all concerned and seriously interfered with proper scientific evaluation of gonadal steroids, the causes and consequences of their deficiency as well as their treatment. The rumbles from that distant "big bang" still resonate today. And, probably no syndrome experiences the influx of "expert" views from all sorts of walks of life: from endocrinologists and psychiatrists to urological surgeons and gerontologists, from the lay press to the regulatory agencies and from the pharmaceutical to the entertainment industries. The dismal result of all this free-forall cacophony of opinions is a great deal of confusion, erroneous information and significant detriment to patients and physicians alike. ${ }^{1}$

Both my opponent and I are believers in the concept of testosterone deficiency syndrome (TDS) and prescribers of testosterone therapy. We may argue about issues of limited consequence such as taxonomy and semantics, but on the fundamental ones (e.g., clinical relevance of the syndrome, its assessment and monitoring therapy), I wish to reiterate that a "con" position is defensible only when TDS is diagnosed and managed incompetently.

The absurd view that TDS is an invention of industry blatantly and conveniently ignores medical observations and reports going back 500 years and accelerating since the mid 20th century. It does not merit further discussion.

Medical progress brings honest disagreements and evolving opinions. The controversy about TDS spans the whole spectrum, from diagnosis to treatment. Two areas are particularly unsettled: the biochemical diagnosis and the effect of testosterone on prostate health. Two other subjects are relatively new but gaining relevance and importance: the contribution of TDS to the development of the metabolic syndrome and erectile dysfunction and their treatment. But heavily debated issues also include the contribution of diagnostic questionnaires, the most effective delivery forms for testosterone, the long-term efficacy and safety of current preparations, standards for monitoring men receiving exogenous testosterone and, most unfortunately, the unwarranted extrapolation of the results of the Women's Health Initiative (WHI) to the use of testosterone treatment in adult men. Although much has been learned over the last 6 decades about the manifestations of 
TDS, the efficacy of testosterone treatment and its potential adverse outcomes, most studies have been relatively short or insufficiently powered to reach definitive conclusions.

Volumes could be written just to address the issues listed above. Allow me to tackle some of the more relevant ones.

\section{Diagnosis}

In addition to an adequate history and physical examination, physicians have several specific options to reach a diagnosis of TDS: questionnaires and a biochemical assessment from peripheral blood (the efficacy of salivary testosterone measurements is currently not fully recognized).

A variety of questionnaires are available at present. Some are more elaborate than others. They are appropriate purely as screening instruments and are documented for their significant sensitivity but rather poor performance with regard to specificity. ${ }^{2}$ Three questionnaires are most widely recognized: the St. Louis University ADAM, the Massachusetts Male Aging Study (MMAS) and the Aging Male Survey (AMS). Owing to their simplicity and sensitivity, the ADAM and the AMS have gained most popularity. Dr. Casey and I share the view that they are helpful for screening purposes but that they fall short in their use as definitive clinical diagnosis or as outcome measures for treatment. $^{3}$

The biochemical diagnosis is another sore point of controversy and confusion, but it is simpler than it has been made out to be: liquid chromatography tandem spectrometry remains the gold standard, and free testosterone by equilibrium dialysis and measured bioavailable testosterone, properly performed, are reliable assays. ${ }^{4}$ These methods, however, are either cumbersome, difficult to reproduce, expensive or not readily available. Calculated free testosterone and bioavailable testosterone are considered accurate and can be carried out with equipment and expertise available in most clinical laboratories. It must be emphasized that the measurement of total testosterone is adequate for the determination of androgenicity in nearly all clinical situations as long as the blood sampling is done in the morning (another point of contention). One must remember the circadian and ultradian variations in testosterone levels. Therefore, the performance of repeat- ed measurements is recommended to confirm the diagnosis. It would be unforgivable to subject a man to a lifetime of testosterone treatment on the basis of a single faulty biochemical test. We should not ignore the small but convincing evidence that assessment of testosterone from samples of peripheral blood might be a poor reflection of androgen levels in tissues. ${ }^{5}$ One last word to the wise on this, from a recent publication:

We have the technology to improve the accuracy and precision of testosterone assays and must choose these properties over simplicity and economy. ${ }^{6}$

Although this is an accurate statement, it is a hard pill to swallow with the realities of our health care system.

\section{Prostate health}

Prominent among the concerns regarding testosterone treatment is its effect on prostate health. For decades, the concept that testosterone is "bad for the prostate" has gone unchallenged. More research and clinical experience are seriously and fundamentally revisiting these notions.' Basic investigations have shown that the development and growth of prostate cancer are much more complex than simply an excess of lack of androgens: nonsteroidal hormones (e.g., insulin, leptin, glucocorticoids and growth hormone), genetic susceptibility, inflammation and environmental factors appear to be significant contributors. Further, and despite the large body of support for a positive relation between male sex steroids and growth of prostate cells, there are a number of puzzling situations that are under active study. For instance, a prostate cancer cell line that requires initial stimulation by androgens to grow is eventually suppressed by them. These and other observations must not be interpreted as a green light for the indiscriminate use of testosterone treatment in adult men. Appropriate assessment of the prostate before and during treatment remains a mandatory responsibility for the treating physician. ${ }^{8}$

I trust that Dr. Casey joins $\mathrm{me}^{9}$ in supporting the recommendation that known or suspected prostate carcinoma is a contraindication for testosterone products. This has been reiterated, unambiguously, by the recent Endocrine Society Guideline. ${ }^{10}$ Administration of testosterone and other steroids 
to men suspected of having prostate cancer, at this time, should be considered only as part of properly sponsored, well designed and organized, rigidly controlled and carefully monitored clinical trials. To do otherwise can easily be construed as reckless behaviour that would potentially endanger the patient's health and the clinician's reputation and result in further detriment to a field already replete with myths, misinformation and dubious evidence. To the objective observer, it is clear that further "critical assessment" of the available information on the relation between testosterone and prostate health will not significantly enhance our knowledge on this topic. Only a fresh approach with good studies will lead to the answers that we all yearn for. ${ }^{9}$

\section{Sexual dysfunction}

An evolving concept in the field of erectile dysfunction is the relevance of androgens in general and testosterone in particular. Experimental evidence for the fundamental importance of androgens in the maintenance of the anatomic and histological integrity of the penile cavernosal structures is overwhelming. ${ }^{11}$ Several clinical studies have confirmed an improvement in sexual desire and erectile quality in testosterone deficient men treated with exogenous testosterone. In addition, there is an ever increasing number of reports indicating that testosterone deficiency interferes not only with normal function but also with the response to treatments specifically aimed at correcting the inadequate mechanisms of erection. The studies are still limited in number and insufficiently powered but intriguing, if not yet totally convincing. Suffice it to say that after several years of doubts and controversy it appears that a simple testosterone determination should be part of the initial work up of most men with erectile dysfunction. If TDS is documented, it should be treated initially; it may be all that is necessary. If, on the other hand, the response is inadequate, the addition of a specific agent (i.e., a PDE5 inhibitor) can be added. ${ }^{12}$

\section{Cardiovascular health}

Significant benefits in some aspects of lipid profile, prevention of atheromas deposition, coronary vasculature and in exercise performance in men with heart failure have been clearly documented. The studies are still few in number ${ }^{13,14}$ or involve small populations. ${ }^{15}$ But, if we are going to reject the results of these well thought out and executed studies, I would say "show me the contrary evidence" or even better, "where is the beef?"

There are many other issues of relevance when dealing with TDS that require the serious attention of the medical and scientific communities. Regulatory agencies base their decisions on published information and expert opinions. Contradictory information from discrepant or poorly developed guidelines and recommendations, studies of questionable design or execution, and the erroneous or tendentious interpretation of their data do not advance our search for answers. The lay media has had a field day pointing to the honest doubts and concerns of serious clinicians and researchers as examples of blatant ignorance at best and dishonesty at worst. Although to a great extent it has been our own fault, the patients and the physicians themselves have ultimately become the victims of this regrettable state of affairs.

From the Centre for Applied Urological Research, General Hospital and Queen's University, Kingston, Ont.

The positions provided in the Point/Counterpoint series are presented as general information and do not necessarily reflect the personal opinions of the authors.

This article has been peer reviewed.

Competing interests: None declared.

\section{References}

1. Lewis BH, Legato M, Fisch H. Medical implications of the male biological clock. JAMA 2006;296:2369-71.

2. Morley JE, Perry HM III, Kevorkian RT, et al. Comparison of screening questionnaires for the diagnosis of hypogonadism. Maturitas 2006;53:424-9.

3. Morales A, Spevack M, Emerson L, et al. Adding to the controversy: pitfalls in the diagnosis of TDS with questionnaires and biochemistry. Aging Male 2007;10:57-66.

4. Wang C, Cattin DH, Demers LM, et al. Measurement of total serum testosterone in adult men: a comparison of current laboratory methods versus liquid chromatography-tandem mass spectrometry. J Clin Endocrinol Metab 2004;89:534-43.

5. Marks LS, Mazer NA, Mostaghel E, et al. Effect of testosterone replacement therapy on prostate tissue of men with late onset hypogonadism. JAMA 2006;296:2351-61.

6. Rosner W, Auchus RJ, Azziz R, et al. Utility, limitations and piffalls in measuring testosterone: An Endocrine Society Position Statement. J Clin Endocrinol Metab 2007;92: 405-13.

7. Morgentaler A. Testosterone and prostate cancer: an historical perspective on a modern myth. Eur Urol 2006;50:935-9.

8. Morales A. Testosterone and prostate health: debunking myths demands evidence, caution and good clinical judgment. Eur Urol 2006;50:895-7. 
9. Morales A, Buvat J, Gooren ป, et al. Endocrine aspects of sexual dysfunction in men. I Sex Med 2004; 1:69-81.

10. Bhasin S, Cunningham GR, Hayes FJ, et al. Testosterone therapy in adult men with androgen deficiency syndromes: an Endocrine Society Clinical Practice Guideline. J Clin Endocrinol Metab 2006;91:1995-2010.

11. Traish AM, Guay AT. Are androgens critical for penile erections in humans? Examining the clinical and predinical evidence. J Sex Med 2006;3:382-404.

12. Black AM, Day AG, Morales A. The reliability of clinical and biochemical assessment in symptomatic late onset hypogonadism: Can a case be made for a 3-month therapeutic trial? BJU Int 2004;94:1066-70

13. Hak AE, Witterman JCM, deJong FH, et al. Low levels of endogenous androgens increase the risk of atherosclerosis in elderly men: the Rotterdam Study. J Clin Endocrinol Metab 2002;87:3632-9.

14. Malkin CJ, Pugh PJ, West J, et al. Testosterone therapy in men with moderate severity heart failure: a double blind randomized placebo controlled trial. Eur Heart $\rfloor$ 2006;27:57-64.

15. Malkin CJ, Pugh PJ, Morris PD, et al. Testosterone replacement in hypogonadal men with angina improves quality of life. Heart 2004;90:871-6.

Correspondence: Dr. A. Morales, Centre for Applied Urological Research, 62 Barrie St., Kingston ON K7L 3J7; morales@post.queensu.co

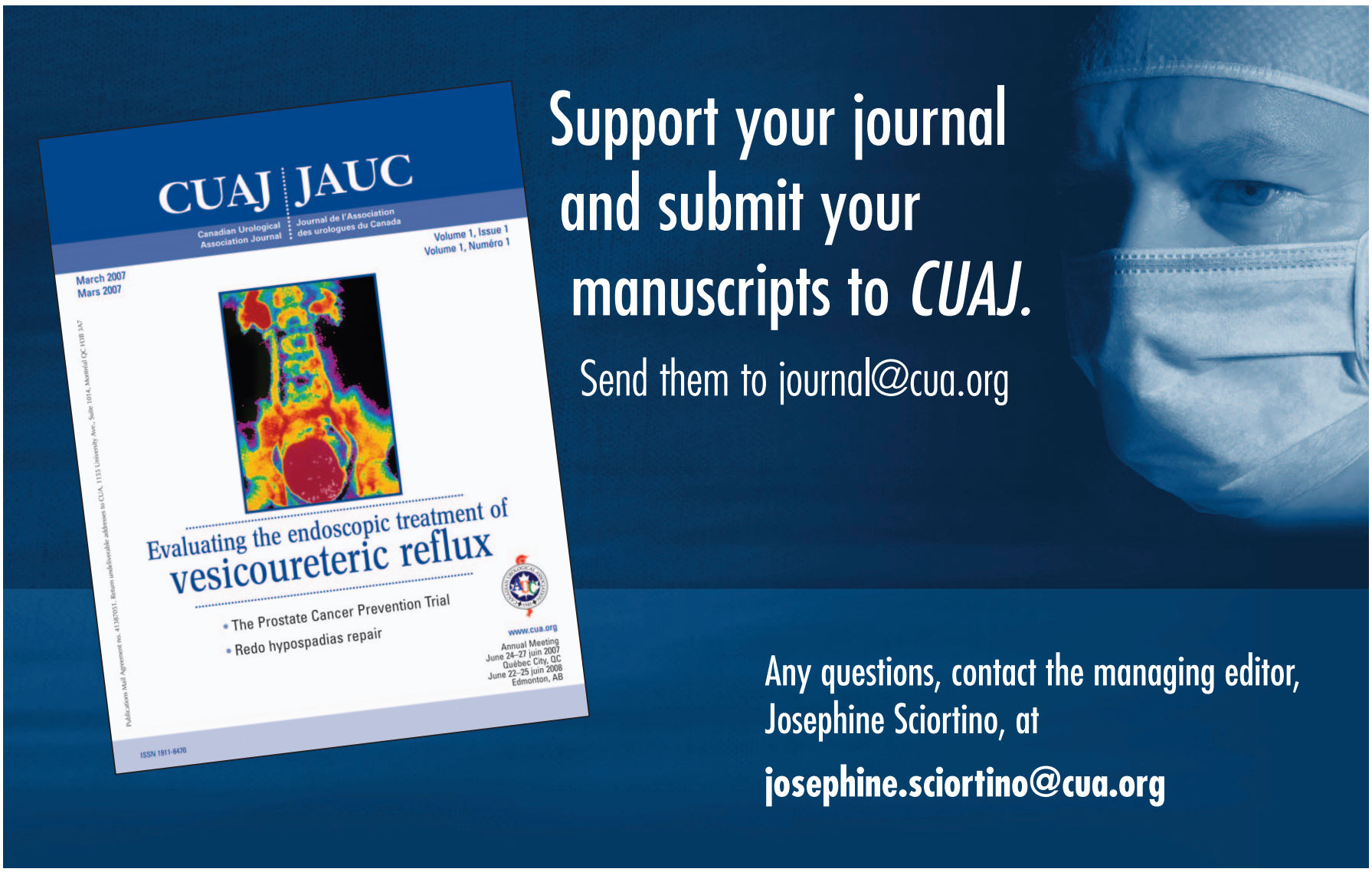




\title{
The use of hormonal therapy in "andropause": the con side
}

\author{
Richard Casey, Bsc, MD, FRCS(C)
}

$\mathrm{T}$ hree physicians are out duck hunting without a license, a family doc, an internist and a surgeon. Not much is happening but they're not going home empty handed. I know you've heard it, but bear with me, there's a point here. After a while, a flock of birds fly over the docs as they hide in the tall grass. The family doc stands up, and with his pistol, shoots at what he thinks is a duck ... wings it, but it keeps flying. Another shot, a few feathers fly, but no birds fall. "You're not very good," says the internist. "You need a rifle anyway."

Hours later and another bunch of birds, the internist jumps up with his high-powered sighted rifle, lines up a bird, then another and another ... not sure if they are ducks, he doesn't want to kill a pigeon. By the time he decides on his target, it's out of range. "I need more time," says the internist, "and maybe a better rifle."

Hours pass and it's almost evening. What looks like birds appear in the twilight sky and now it's the surgeon's turn. With his blunt, 12 gauge shotgun, he sprays the flock. All 3 docs are pelted with dead birds, among them sparrows, pigeons and geese. "There's a duck there somewhere," the surgeon boasts. "Now can we go home?"

Why the old joke? Unfortunately the use of testosterone replacement therapy continues to be a bit of a duck hunt. I cannot completely disagree with Dr. Morales. The end organ effects of testosterone are remarkable. Improved strength, better mood, stronger muscles, increased libido, the list goes on. If we only knew where to use this weapon! In the truly hypogonadal patient, one cannot argue the benefits of testosterone replacement therapy. Fortunately for our patients, and unfortunately for the manufacturers of testosterone therapies, hypogonadal symptomatic males are few and far between, and would never support the infrastructure around the present testosterone replacement therapy market. There just aren't enough ducks to keep everyone in business, and Dr. Morales wants us to consider treating pigeons under the guise of andropause.

My position is that andropause is primarily a market-driven concept, largely promoted by industry, accepted by a handful of physicians and embraced by some patients who are looking for an antidote to aging. We need to resist the marketing efforts and consider the science.

Briefly summarized, we know plenty about the effects of testosterone but little about the indications, benefits and long-term safety in the population targeted with the andropause shotgun.

The range of normal testosterone levels is quite broad; levels depend on time of day and no consensus exists on what measurement of testosterone (total, free or bioavailable) correlates best with symptoms or treatment success. There is a gradient between the truly hypogonadal patient and the softer andropausal male. Clinical judgment is necessary to determine who will benefit from treatment.

But the symptom complex associated with andropause (or the "newer" term symptomatic lateonset hypogonadism) is ill-defined and shares similar characteristics with depression, normal aging and, for lack of appropriate medical terminology, just being overweight and lazy! There are no good validated instruments to help the physician determine who will improve on treatment or measure the treatment effects.

Add to the mix the lack of good randomized prospective clinical data on the long-term effects and no information on the cost benefits - why do physicians continue to prescribe testosterone replacement therapy to essentially eugonadal men?

One answer would be that industry is driving the market and recent prescription data would support this. Sales visits to physicians are way down and testosterone sales are flat. It's expensive to support a concept as nebulous as andropause! Another might be that physicians are lazy and would rather end the interview with a prescription than a lifestyle lecture! I think most of us remain confused on who's likely to benefit and are experimenting a bit.

Few physicians have incorporated screening for hypogonadal patients into their routines despite the cry from Dr. Morales and his band of testosterone- 
toting docs. We are all narrowing our sights; metabolic syndrome (i.e., obesity and diabetes) and conditions that are associated with low testosterone where there is the possibility that testosterone might improve clinical outcomes is where most physicians are hunting today. Industry has begun to follow suit and the currently available educational kits are more focused but still suggest a shotgunlike approach.

Also, if there is a symptom complex that will respond to exercise better than andropause, I don't know of it. Educational material produced by industry mentions exercise in passing and testosterone docs spend little time educating their patients on the health benefits of physical activity. Here's an idea for your patients: tell them to take the \$1200 they'll spend on testosterone per year and join a health club; buy a Stairmaster - they'll have money leftover for their new clothes!

Until industry supports the science behind testosterone replacement therapy, it will always be a therapy used "in good faith." I need more long-term controlled data before I can recommend testosterone replacement therapy to my male patients with soft symptoms and borderline testosterone levels. I need tools to measure progress and some idea of the cost-effectiveness. Finally, we all need industry to pay for a license (proper trials) and to stop asking us to hunt for them. Until then andropause remains a pigeon masquerading as a duck and no one, especially the other birds, want us to hunt like surgeons.

Director, The Male Health Centres, Oakville, Ont.

The positions provided in the Point/Counterpoint series are presented as general information and do not necessarily reflect the personal opinions of the authors.

This article has been peer reviewed.

Competing interests: Dr. Casey is a member of the Solvay Pharmaceuticals Advisory Board and of the Paladin Labs Advisory Board.

Correspondence: Dr. R. Casey, Director, The Male Health Centres, 407-1235 Trafalgar Rd. N., Oakville ON L6H 3PI; drcasey@on.aibn.com 


\section{Dr. Morales' Rebuttal}

I t looks like a duck, flies like a duck, walks like a duck, quacks like a duck: it must be a pigeon! I hope the CUAJ readership will enjoy Dr. Casey's comments as much as I did. His sense of humour is legendary. Regrettably, it falls short of the scientific evidence expected and demanded for a topic that must be addressed with utmost seriousness. His allegations against industry are unfounded, old and tired, and do not match credible epidemiological verification from unimpeachable sources. ${ }^{1-2}$ No evidence exists to refute these solid studies, unless my distinguished opponent is keeping secrets from us. Just one little reference to support your argument and for our own edification, Dr. Casey?

More serious is his charge that there is a medical profession easily manipulated by industry in prescribing unnecessary medications for some kind of undefined benefits. This should not be taken lightly and one hopes that such an accusation is based on fact and not just gut feelings. We all know what happens when medicine is guided by gut feelings. When he mentions the flattening of testosterone prescriptions in the last 2 years, Dr. Casey conveniently ignores the remarkable increase in testosterone use over the last 10 years. The use of phosphodiasterase inhibitors to treat erectile dysfunction has also flattened over the last few years (despite the exorbitant amount of free samples available, a practice that is not allowed for testosterone products). With the same logic, are we then to conclude that erectile dysfunction is a figment of the imagination of the manufacturers of PDE-5 inhibitors and a bunch of malleable and, perhaps, not too honest, poorly informed prescribers? Richard, you know better than that!

Who in his or her right mind would object to recommending and practising exercise, adequate diet, elimination of stress, smoking cessation and motherhood? They are all good for endothelial health. Such lofty ideals are commendable but far from reality, particularly in middle-aged and older individuals. Dr. Casey should tell us how many of his numerous "andropausic" patients follow and successfully complete the Casey's Regimen. If he had bothered to look just at the titles of the few references I provided ${ }^{3-9}$ he wouldn't have written that "we ... know little of the indications, benefits and long term safety." ${ }^{10}$ To credibly dismiss evidence, one needs counterevidence.

Let's be careful with what learned societies are recommending. Not one of them and no informed physician would recommend "screening for andropause." I do not know where Dr. Casey got this extravagant idea. What has been recommended is the combination of clinical manifestations plus biochemical confirmation and competent clinical judgment. A biochemical assessment has been recommended only if there are clinical manifestations. Do we have problems with the diagnosis? Of course we do, but this is not uncommon in the practice of medicine (who has not heard of the shortcomings of PSA, the VB1 and VB2, and bladder biopsies for the diagnosis of prostate cancer, prostatitis and interstitial cystitis, respectively?). However, what investigations do Dr. Casey and his group of hunters, huddled inside a blind, without a gun and out of season, propose for a man with the well-recognized picture of "andropause" and in the absence of depression?

We are told by my distinguished colleague that "there are no good validated instruments to measure the treatment effects. ${ }^{10}$ Whoa! They range from the clinical assessment and questionnaires such as the Internationl Index of Erectile Function (IIEF) and Aging Male Survey (AMS) to the improvement in sarcopenia (CT scanning), osteoporosis (dual energy x-ray scan), cognitive function, hematopoiesis (complete blood count), better cardiovascular health (stress test, etc.) ... I could go on and on just listing the validated instruments.

To quote Dr. Casey:

We are all narrowing our sights; metabolic syndrome (i.e., obesity and diabetes) and conditions that are associated with low testosterone where there is the possibility that testosterone might improve clinical outcomes is where most physicians are hunting today. ${ }^{10}$

I couldn't agree more. It might be "where most physicians are hunting today." That the metabolic syndrome became the fashionable and popular condition of today does not recognize those who 
have been quietly researching and discussing it for years. Oh well, many were convinced that the Earth was flat. Some still are.

The positions provided in the Point/Counterpoint series are presented as general information and do not necessarily reflect the personal opinions of the authors.

This article has been peer reviewed.

Competing interests: None declared.

\section{References}

1. Rodriguez A, Muller DC, Metter EJ, et al. Aging, androgens and the metabolic syndrome in a longitudinal study of aging. J Clin Endocrinol Metab 2007;92:2568-72.

2. Araujo AB, Esche GR, Kupelian V, et al. Prevalence of symptomatic androgen deficiency in men. J Clin Endocrinol Metab 2007; 92:424-7.
3. Morales A, Buvat J, Gooren $\downarrow$, et al. Endocrine aspects of sexual dysfunction in men. I Sex Med 2004;1:69-81.

4. Bhasin S, Cunningham GR, Hayes FJ, et al. Testosterone therapy in adult men with androgen deficiency syndromes: An Endocrine Society Clinical Practice Guideline. J Clin Endocrinol Metab 2006;91:1995-2010.

5. Traish AM, Guay AT. Are androgens critical for penile erections in humans? Examining the clinical and predinical evidence. I Sex Med 2006;3:382-404.

6. Black AM, Day AG, Morales A. The reliability of clinical and biochemical assessment in symptomatic late onset hypogonadism: can a case be made for a 3-month therapeutic trial? BJU Int 2004;94:1066-70.

7. Hak AE, Witterman JCM, deJong FH, et al. Low levels of endogenous androgens increase the risk of atherosclerosis in elderly men: the Rotterdam Study. J Clin Endocrinol Metab 2002;87:3632-9.

8. Malkin CJ, Pugh PJ, West J, et al. Testosterone therapy in men with moderate severity heart failure: a double blind randomized placebo controlled trial. Eur Heart $\rfloor$ 2006;27:57-64

9. Malkin CJ, Pugh PJ, Morris PD, et al. Testosterone replacement in hypogonadal men with angina improves quality of life. Heart 2004:90:871-6.

10. Casey R. The use of hormonal therapy in "andropause": the con side. CUAJ 2008;2:47. 


\section{Dr. Casey's Rebuttal}

will comment on only 3 of Dr. Morales's statements, primarily because I agree with him in principle. Testosterone replacement has a positive effect on sexual and cardiovascular health and probably doesn't directly cause prostate cancer.

Dr. Morales asks for some references to support my argument and "for our own edification." 1 To Dr. Morales and fellow readers I would recommend Darby and Anawalt's article ${ }^{2}$ on diagnosing and treating male hypogonadism, Jockenhövel's paper $^{3}$ on testosterone therapy and Seftel's article ${ }^{4}$ about the pharmacologic monitoring and safety of testosterone therapy.

Dr. Morales states that the "con side is defensible only when TDS is diagnosed and managed incompetently." ${ }^{\prime 1}$ It is difficult to diagnose and manage a disease that hasn't been accurately described! $!^{5}$. Morales admits that there are no good tools and there is significant confusion over the appropriate testosterone measurement to use. Add to this the large grey zone of patients that have low normal or slightly low testosterone levels and some of the soft symptoms of andropause, and we have further ambiguity. A study that stratified these patients by symptoms and testosterone levels and gave us some idea of treatment successes would be helpful. Can't find one. Competence remains an issue for all of us.

"The absurd view that TDS is an invention of industry ... does not merit further discussion"1 is the second statement of interest. Testosterone is a therapy searching for an indication. Ask our primary care physicians and urologists how they feel about andropause and about their success in treating this population. Industry continues to advertise heavily and spend money on marketing and little on the science of testosterone. The most recent meeting of the International Society for the Study of the Aging Male was a testosterone fest and after looking on http://clinicaltrials.gov, ${ }^{6} \mathrm{I}^{\prime}$ ve yet to find a trial registered that will help us determine who, outside the profoundly hypogonadal male who is not in question here, will benefit from testosterone replacement therapy. Until we have more science, testosterone replacement therapy for the andropausal man will remain in the antiaging section along with Botox, hair transplantation and a myriad of natural supplements. Unfortunately, our patients, not Industry, will be paying for the observational data.

The positions provided in the Point/Counterpoint series are presented as general information and do not necessarily reflect the personal opinions of the authors.

This article has been peer reviewed.

Competing interests: Dr. Casey is a member of the Solvay Pharmaceuticals Advisory Board and of the Paladin Labs Advisory Board.

\section{References}

1. Morales A. The use of hormonal therapy in "andropause": the pro side; rebuttal. CUAJ 2008;2:43; 49

2. Darby E, Anawalt BD. Male hypogonadism: an update on diagnosis and treatment. Treat Endocrinol 2005;4:293-309.

3. Jockenhövel F. Testosterone therapy - what, when and to whom? Aging Male 2004;7:319-24.

4. Seftel A. Testosterone replacement therapy for male hypogonadism: part III. Pharmacologic and clinical profiles, monitoring, safety issues, and potential future agents. Int J Impot Res 2007;19:2-24.

5. Kazi M, Geraci SA, Koch CA. Considerations for the diagnosis and treatment of testosterone deficiency in elderly men. Am J Med 2007;120:835-40.

6. Clinicaltrails.gov: a service of the US National Institutes of Health. Available: http:// clinicaltrials.gov/ (accessed 2007 Dec 30). 